\title{
Insect cells are superior to Escherichia coli in producing malaria proteins inducing lgG targeting PfEMP1 on infected erythrocytes
}

\author{
Michala E Victor ${ }^{1 \dagger}$, Anja Bengtsson ${ }^{1 \dagger}$, Gorm Andersen', Dominique Bengtsson ${ }^{1}$, John P Lusingu ${ }^{1,2}$, \\ Lasse S Vestergaard', David E Arnot ${ }^{1,3}$, Thor G Theander', Louise Joergensen', Anja TR Jensen ${ }^{1 *}$
}

\begin{abstract}
Background: The PFD1235w Plasmodium falciparum erythrocyte membrane protein 1 (PfEMP1) antigen is associated with severe malaria in children and can be expressed on the surface of infected erythrocytes (IE) adhering to ICAM1. However, the exact three-dimensional structure of this PfEMP1 and its surface-exposed epitopes are unknown. An insect cell and Escherichia coli based system was used to express single and double domains encoded by the pfd1235 $\mathrm{W}$ var gene. The resulting recombinant proteins have been evaluated for yield and purity and their ability to induce rat antibodies, which react with the native PFD1235w PFEMP1 antigen expressed on 3D7PFD1235w-IE. Their recognition by human anti-malaria antibodies from previously infected Tanzanian donors was also analysed.

Methods: The recombinant proteins were run on SDS-PAGE and Western blots for quantification and size estimation. Insect cell and E. coli-produced recombinant proteins were coupled to a bead-based Luminex assay to measure the plasma antibody reactivity of 180 samples collected from Tanzanian individuals. The recombinant proteins used for immunization of rats and antisera were also tested by flow cytometry for their ability to surface label 3D7 PFD1235w-IE.
\end{abstract}

Results: All seven pAcGP67A constructs were successfully expressed as recombinant protein in baculovirus-infected insect cells and subsequently produced to a purity of 60-97\% and a yield of 2-15 mg/L. By comparison, only three of seven pET101/D-TOPO constructs expressed in the E. coli system could be produced at all with purity and yield ranging from 3-95\% and 6-11 mg/L. All seven insect cell, but only two of the E. coli produced proteins induced antibodies reactive with native PFD1235w expressed on 3D7 7 PD1235w - IE. The recombinant proteins were recognized in an age- and transmission intensity-dependent manner by antibodies from 180 Tanzanian individuals in a beadbased Luminex assay.

Conclusions: The baculovirus based insect cell system was distinctly superior to the $E$. coli expression system in producing a larger number of different recombinant PFD1235w protein domains and these were significantly easier to purify at a useful yield. However, proteins produced in both systems were able to induce antibodies in rats, which can recognize the native PFD1235w on the surface of IE.

\footnotetext{
* Correspondence: atrj@sund.ku.dk

† Contributed equally

${ }^{1}$ Centre for Medical Parasitology, Department of International Health, Immunology and Microbiology, Faculty of Health Sciences, University of

Copenhagen and Department of Infectious Diseases, Copenhagen University Hospital (Rigshospitalet), CSS Oester Farimagsgade 5, Building 22 \& 23, PO

2099, 1014 Copenhagen K, Denmark

Full list of author information is available at the end of the article
} 


\section{Background}

Malaria remains a devastating infectious disease, with the parasite Plasmodium falciparum being responsible for killing approximately one million children below the age of five each year [1]. Development of an effective malaria vaccine would have a profound impact on the control of the disease as drug resistance toward affordable, effective drugs continues to emerge. However, since nearly $60 \%$ of hypothetical proteins in the parasite genome are of unknown function, much needs to be learned about the biology of the parasite. In particular, identifying parasite antigens that elicit long-lasting protective immune response has proven very difficult [2].

In the discovery and characterization of new vaccine candidates, bioinformatics tools are useful, but protein function and structure cannot be definitely determined from exclusively in silico experiments. However, sufficient quantities of the "protein of interest" cannot usually be isolated from either host infection or in vitro culture host. Therefore, heterologous expression of soluble and functional parasite proteins is key to progress toward identification of new vaccine candidates.

The classic genetic model bacterium, Escherichia coli, is still a preferred organism for heterologous expression of recombinant proteins, largely due to cost considerations, speed, ease of use and genetic manipulation. But for many proteins the bacterial cell often does not produce satisfactory results [3]. Obstacles to the efficient expression of Plasmodium proteins in bacteria are their usually high molecular weight (>56 kDa), more basic $\mathrm{pI}$ (> 6), lack of homology to bacterial proteins, Plasmodium-specific inserts, often apparently disordered sequences, transmembrane regions, signal peptides, disulphide bridges and export motifs [4-6]. In addition to $E$. coli, several other organisms have, therefore, been employed to attempt to improve heterologous expression, including baculovirus-infected insect cells [7]. This system has the advantage of usually permitting production of high molecular weight recombinant proteins, with recognition of normal eukaryotic targeting signals and post-translational machinery. However, the baculovirus expression system requires an increased investment time and uses higher cost media compared to bacteria, and it is technically more challenging [3].

Producing recombinant proteins retaining natural folding is essential for elucidating the three dimensional structure of malaria proteins and for determining which structural epitopes are exposed on the surface of IE during natural malaria infections. Both bacteria and insect cells have been shown to express Plasmodium proteins, which retained conformational epitopes and elicited antibody responses [8-10], and both systems have produced recombinant merozoite surface protein 1 (MSP1) capable of acting as a protective immunogen and capable of protecting mice and monkeys from malaria challenge $[11,12]$. Existing data thus do not indicate that one heterologous expression system is definitely superior to the other and although bioinformatics tools can predict solubility and aid the design of suitable domains for heterologous expression, such predictions are not powerful and the identification of the optimal system for heterologous expression remains a matter of experimental testing.

The $P$. falciparum erythrocyte membrane protein 1 (PfEMP1) proteins are implicated in two key biological phenomena in malaria; antigenic variation and sequestration $[13,14]$, and have, therefore, been proposed as candidates for a blood stage vaccine [15]. The PfEMP1 proteins are encoded by the var gene family, with approximately 60 genes per haploid genome. Each gene consists of a highly variable 5' exon encoding an extracellular region and a single transmembrane domain, a relatively conserved intron, and a highly conserved 3 ' exon encoding an intracellular region of the transmembrane protein. The var genes vary in size from $6-15 \mathrm{~kb}$ and encode PfEMP1 proteins ranging in size from $200-500 \mathrm{kDa}$, the variable extracellular region being composed of several distinct domain structures; the N-terminal segment (NTS, 75-100 aa), Duffy-binding like domains (DBL, $\alpha-\varepsilon, 100-250$ aa) and the cysteine-rich interdomain (CIDR, $\alpha-\gamma, 70-200$ aa) $[2,16]$. A few higher order arrangements of the domains are conserved, such as the NTS-DBL1 $\alpha$-CIDR $1 \alpha$ combination always found at the amino terminus (referred to as the head structure) and the DBL $\delta$-CIDR $\beta / \gamma$ tandem pairing $[17,18]$.

The high molecular weight of the full-length PfEMP1 proteins complicates full-length heterologous expression, and the PfEMP1 proteins are usually expressed as single or double domains. However, even though the size of single domains are compatible with most expression systems, they still encompass biochemical and physical characteristics, such as a high number of disulphide bridges and a basic pI $(>6)$, that, in theory, make recombinant expression difficult.

In previous studies $[19,20]$, the parasite expression of the PfEMP1 protein encoded by the var pfd1235w gene, was found to be associated with severe childhood malaria. However, the exact role of the PFD1235w protein during childhood malaria infections, including definition of the domain/motif binding host endothelium ICAM1 and identification of immunodominant epitopes remains to be established. Such studies require an expression system producing experimentally useful quantities of recombinant PFD1235w protein, with a native fold. To address this issue, an E. coli and baculovirus expression system was used to express single and double domains from the extracellular region of the PFD1235w protein. The resulting proteins were 
evaluated in terms of yield and purity, ability to induce antibodies reactive with native PFD1235w expressed on the surface of IE and their recognition by Tanzanian immune plasma.

\section{Methods}

\section{Protein expression}

The 3D7 DNA sequences encoding the PFD1235w protein domains listed in Additional file 1 was PCR amplified, cloned and expressed in a baculovirus insect cell system as described $[19,21,22]$. Supernatants with secreted recombinant protein were diafiltered on an ÄKTAcrossflow (GE Healthcare) using Buffer A (20 mM sodium phosphate, $500 \mathrm{mM}$ sodium chloride, $\mathrm{pH}$ 7.5) plus $10 \mathrm{mM}$ imidazole prior to purification on a HISselect Cartridge column (Sigma-Aldrich). Bound recombinant protein was eluted using a one-step procedure and Buffer A including $200 \mathrm{mM}$ imidazole. Following dialysis against buffer $\mathrm{A}$ the final protein concentration was measured at $\mathrm{UV}_{280 \mathrm{~nm}}$.

Similarly, 3D7 pfd1235w DNA sequences (Additional file 1) were PCR amplified and cloned in the E. coli pET101/D-TOPO vector by blunt-end ligation, recombinant plasmid transfected into the Rosetta-gami B (DE3) E. coli strain with improved cytoplasmic disulphide bond formation (Novagen) and protein expressed in $2 \mathrm{x} \mathrm{YT}$ media $(1.6 \%(\mathrm{w} / \mathrm{v})$ Bacto tryptone, $1 \%(\mathrm{w} / \mathrm{v})$ yeast extract, $0.5 \% \mathrm{NaCl}, \mathrm{pH} 7.5)$ using the Champion ${ }^{\mathrm{TM}} \mathrm{pET}$ Directional $\mathrm{TOPO}^{\circ}$ Expression Kit as described (Invitrogen).

In brief, following dilution (1:100) of overnight cultures cells were grown to $\mathrm{OD}_{600}=1$ at $16-21^{\circ} \mathrm{C}$ and induced with 10-1000 $\mu \mathrm{M}$ IPTG for 20 hours. Prior to large scale protein production the optimal IPTG concentration and temperature for induction of protein expression from each construct was determined in a pilot experiment using 10, 100, $1000 \mu \mathrm{M}$ IPTG and incubating at $37^{\circ} \mathrm{C}$ for 3 hours, room temperature for 20 hours, and $4^{\circ} \mathrm{C}$ for 20 hours. The different IPTG concentrations only yielded minor differences in expression levels and in most cases $10 \mu \mathrm{M}$ was used for large scale protein production. Similarly, varying the temperature only had a slight impact on expression levels with incubation at room temperature for 20 hours giving the highest yield. Following harvesting, cell pellets were resuspended in $20 \mathrm{ml}$ Buffer A plus $10 \mathrm{mM}$ Imidazole and a Complete Mini Protease Inhibitor Tablet without EDTA (Roche). Following sonication, centrifugation and filtration supernatants were purified on a HISTrapHP column (GE Healthcare). Elution, dialysis and estimation of protein concentration was carried out as described above.

\section{SDS-PAGE and Western blotting}

For purity and quality estimation $2 \mu \mathrm{g}$ of each purified recombinant protein, both reduced (+DTT) and non- reduced (- DTT), was separated on a NuPAGE ${ }^{\oplus}$ Novex 4-12\% Bis-Tris gel in MOPS SDS Running buffer (Invitrogen) and detected using BioSafe coomassie stain (BIO-RAD). ProSieve Color Protein marker (Lonza) was used for calibration and Quantity One software (BIORAD) for protein quantification and size estimation. Western blotting was done using standard techniques. In brief, $0.2 \mu \mathrm{g}$ purified protein was separated, blotted onto a Hybond ${ }^{\mathrm{TM}}-\mathrm{C}$ Extra membrane (Amersham BioSciences), and detected by an anti-V5-HRP antibody (Invitrogen) using a Chemiluminescent detection kit (Pierce).

\section{Plasma samples}

The plasma samples were obtained during a cross-sectional survey in April 2001 as part of a longitudinal study characterizing malaria morbidity and immunity among individuals living in Mgome, Ubiri, and Magamba village in the Tanga region of Northeastern Tanzania. The point prevalence of P. falciparum in the three different villages was $81 \%$ (Mgome), 41\% (Ubiri), and $12 \%$ (Magamba) [23]. Prior to this study, informed consent was obtained from all studied individuals and/ or their parents and ethical clearance was granted by the Ministry of Health and the Ethics Committee (National Institute for Medical Research, Tanzania). For this study, 15 samples from each of four predefined age groups $(2-4,5-9,10-14$, and 15-19 years) were randomly picked and used for Luminex plex analysis of antibody reactivity to purified recombinant insect cell and $E$. coli produced proteins. All plasma samples represented individuals with a previous history of malaria, but no clinical symptoms at the time of sampling. Samples from 20 Danish donors with no previous exposure to malaria were included as controls.

\section{Luminex}

The antibody reactivity of human plasma samples were tested in the BioPlex ${ }^{100}$ System (BioRad) as previously described [24]. Briefly, $50 \mu \mathrm{g}$ of six insect cell (DBL1 $\alpha$ CIDR $1 \alpha$, CIDR $1 \alpha$, DBL3 $\beta$, DBL $4 \gamma$, DBL $5 \delta$, DBL $5 \delta-$ CIDR2 $\beta$ ) and two E. coli (DBL3 $\beta$, DBL $4 \gamma$ ) produced proteins were individually coupled to $6.25 \times 10^{6}$ Luminex xMAP technology microsphere beads (Ramcon). Diluents used were PBS/TB (PBS, 0.05\% (v/v) Tween-20, $0.1 \%(\mathrm{w} / \mathrm{v}) \mathrm{BSA}, \mathrm{pH} 7.4)$. Prior to multiplexing, protein coupling was verified by incubating 1250 coupled beads with $1: 100$ to $1: 1000,000$ mouse anti-V5 antibody (Invitrogen) followed by biotinylated anti-mouse IgG (1:1000, DakoCytomation). The biotinylated antibody was detected using PE-streptavidin (1:1000, Invitrogen). Multiplexed beads $\left(1.88 \times 10^{4}\right.$ per protein per well $)$ were incubated with 180 different individual Tanzanian plasma samples $(1: 1300)$ followed by PE-conjugated 
anti-human IgG (1:3200, Jackson Immunoresearch). Beads were resuspended in $100 \mu$ liluents and a minimum of 100 beads from each set of multiplexed beads were analyzed to yield the mean fluorescence intensity (MFI). To test for inter-plate variation, each plate included a pool of positive plasma titrated 2-fold from $1: 40$ to $1: 20,480$ in addition to a negative buffer control. Antibody reactivity of individual plasma samples was calculated as $\mathrm{MFI}_{\text {sample }}$ minus $\mathrm{MFI}_{\text {buffer. }}$ For each of the proteins the PBS buffer corrected mean MFI value plus three standard deviations obtained with plasma from 20 Danish blood donors without previous exposure to malaria was used as a negative cut-off value.

\section{Generation of antisera}

All procedures complied with European or national regulations. Prior to immunization each animal was prebled and these sera were used as negative controls. Polyclonal rat antisera (2-3 rats per protein) were raised by subcutaneous injection of $25 \mu \mathrm{g}$ recombinant protein in complete Freund's adjuvant followed by several boosters of $15 \mu \mathrm{g}$ protein in incomplete Freund's adjuvant. Additional bleeds were collected during and following the completion of the immunization scheme.

\section{Blocking of antibodies}

Rat PFD1235w DBL1 $\alpha$-CIDR1 $\alpha$, DBL3 $\beta$, DBL4 $\gamma$ antisera binding was blocked by incubation for $1 \mathrm{hr}$ at $4^{\circ} \mathrm{C}$ using excess purified recombinant homologous or heterologous produced protein $(100 \mu \mathrm{l}$ of $0.1 \mathrm{mg} / \mathrm{ml}$ protein in each well containing $5 \mu \mathrm{l}$ rat serum) and remaining antibody reactivity to native PFD $1235 \mathrm{w}$ expressed on the

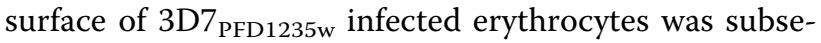
quently tested by flow cytometry as described below. The resulting reduction in serum reactivity was calculated as $\left(\left(\mathrm{MFI}_{\text {sample }}-\mathrm{MFI}_{\min }\right) / \mathrm{MFI}_{\max }\right) * 100 \%$ with MFImin being the signal obtained with addition of secondary antibody, but no antiserum and $\mathrm{MFI}_{\max }$ the signal obtained with addition of serum and secondary antibody, but no blocking protein prior to testing by flow cytometry.

\section{Malaria parasite cultivation and in vitro selection procedure}

The P. falciparum 3D7 clone was cultured in blood group 0 erythrocytes as previously described [25]. Cultures were routinely genotyped by PCR using primers targeting the polymorphic loci MSP2 and GLURP as described [26], and mycoplasma tested using the MycoAlert ${ }^{\circledR}$ Mycoplasma Detection Kit (Lonza) following the manufactures instructions. IgG from rabbits immunized with DBL4 $\gamma$ of 3D7 PFD1235w expressed in insect cells were used to in vitro select a previously selected 3D7 line [27]. Briefly, the rabbit sera were depleted on human uninfected erythrocytes type 0 , incubated with gelatine purified trophozoite-stage 3D7 parasites for 30 min at $37^{\circ} \mathrm{C}$, and unbound antibodies were removed by washing. Subsequently, IE were incubated with Protein A-coupled Dynabeads ${ }^{\oplus}$ (Invitrogen) for $30 \mathrm{~min}$ at $37^{\circ} \mathrm{C}$ and bound IE were trapped using a magnet. Trapped IE were transferred to new culture flasks for continued in vitro culturing and the procedure was repeated until cultures stained positive by the selecting antisera in flow cytometry.

\section{Flow cytometry}

Flow cytometry surface staining was done with minor modifications as described in Staalsoe et al., 1999 [25]. Briefly, IE were purified on a magnet-activated cell sorting column (MACS), adjusted to $2 \times 10^{6}$ cells $/ \mathrm{ml}$ and $100 \mu \mathrm{l}$ cells were added to each well of 96 well plates and incubated for $30 \mathrm{~min}$ at $4^{\circ} \mathrm{C}$ with $5 \mu \mathrm{l}$ rat sera depleted of anti-human erythrocyte antibodies. Following, IEs were incubated for $30 \mathrm{~min}$ at $4^{\circ} \mathrm{C}$ with $100 \mu \mathrm{l} /$ well FITC-conjugated goat anti-rat IgG (Zymed) diluted 1:150 in PBS supplemented with $2 \%$ foetal calve serum and ethidium bromide added to a final concentration of $2 \mu \mathrm{g} / \mathrm{ml}$. IEs were analysed on a Cytomics FC $500 \mathrm{MPL}$ flow cytometer (Beckman Coulter), and data analysed using WinList version 6.0 (Verity Software House Inc.). IEs were gated based on the ethidium bromide staining to exclude non-infected erythrocytes. Mean fluorescent intensity (MFI) for individual rat bleeds were related to MFI for the corresponding pre-bleed sample (MFI bleed/MFI pre-bleed), and the sample with the highest relative MFI value for each animal or each immunization group were used for further analysis. A relative MFI value of 1.3 was used as cut-off for discriminating between positive and negative serum samples

\section{Confocal microscopy}

Laser scanning confocal microscopy was performed on samples analysed by flow cytometry in order to observe the staining patterns on individual IE. MACS purified unlabelled infected cells from the same batches of parasites tested by flow cytometry were incubated with individual antibodies as previously described [28]. Briefly, 1 $\mu \mathrm{l}$ packed IE were washed in three times in $100 \mu \mathrm{l} 1 \%$ BSA in PBS (BSA/PBS) and the pellet was incubated in $100 \mu \mathrm{BSA} / \mathrm{PBS}$ and $3 \mu \mathrm{l}$ of the respective antibodies for 30 minutes at $4^{\circ} \mathrm{C}$. The IE were washed three times in BSA/PBS. The IE stained with primary antibody were then incubated with $100 \mu \mathrm{l}$ secondary antibody Alexa $488^{\circ}$ anti-rat IgG (Invitrogen) and DAPI ( $3 \mu$ of a 300 $\mathrm{ng} / \mathrm{ml}$ solution) for 30 minutes at $4^{\circ} \mathrm{C}$. The IE were washed three times in $100 \mu \mathrm{l} 1 \% \mathrm{BSA} / \mathrm{PBS}$ and visualized as live, unfixed cells using a Nikon TE 2000-E confocal Nikon microscope with $60 \times$ oil immersion 
objective lens (DIC). The images were processed using Adobe Photoshop software and displayed with the $5 \mu \mathrm{m}$ scale bar calculated by the EZ-C1 software.

\section{Results}

Yield and purity of recombinant PFD1235w protein

Seven constructs encoding single or double domains from the extra-cellular region of the PfEMP1 protein encoded by $p f d 1235 w$ were made for experimental comparative expression in both insect cells and an E. coli system. Successful expression and purification was achieved with all seven constructs in baculovirusinfected Trichoplusia ni High-5 cells (DBL1 $\alpha$-CIDR1 $\alpha$, CIDR1 $\alpha$, DBL2 $\beta$, DBL3 $\beta$, DBL4 $\gamma$, DBL5 $\delta$-CIDR $2 \beta$, DBL5 $\delta$ ). Three out of seven constructs (CIDR1 $\alpha$, DBL3 $\beta$, DBL4 $\gamma$ ) produced detectable recombinant protein in the Rosetta-gami B (DE3) E. coli strain, which has improved cytoplasmic disulphide bond formation (Figure 1). All recombinant proteins were purified and checked by sodium dodecyl sulfate-polyacrylamide gel electrophoresis and Western blotting as described previously (Figure 2) [19].
Five insect cell-derived proteins were processed to a purity greater than or equal to $80 \%$, whereas similar purity was only achieved with one bacterial expressed domain, DBL4 $\gamma$ (Figure 1). The highest protein yield observed was achieved with the DBL3 $\beta$ in insect cells (app. $15 \mathrm{mg} / \mathrm{L}$ ) with $E$. coli yielding a maximum of 11 $\mathrm{mg} / \mathrm{L}$ for the DBL4 $\gamma$ domain. With regards to estimating the molecular weight of the products, in comparison with the calculated expected molecular weight a $20 \%$ average increase was observed when expressing protein domains in insect cells. This was opposed to an average of $12 \%$ increase observed in the $E$. coli expression system (Figure 2). This $8 \%$ difference in size is explained by glycosylation of the secreted recombinant protein expressed by the insect cells. Degradation of the PFD1235w domains was more pronounced in the E. coli expression system with only DBL4 $\gamma$ showing no sign of degradation (Figure 2). By contrast, DBL1 $\alpha$-CIDR1 $\alpha$, DBL4 $\gamma$, DBL5 $\delta$-CIDR2 $\beta$, and DBL5 $\delta$ expressed in the baculovirus system were purified with no detectable degradation (Figure 2). In addition to this, three additional proteins DBL1 $\alpha$, NTS-CIDR $1 \alpha$, and CIDR2 $\beta$ were

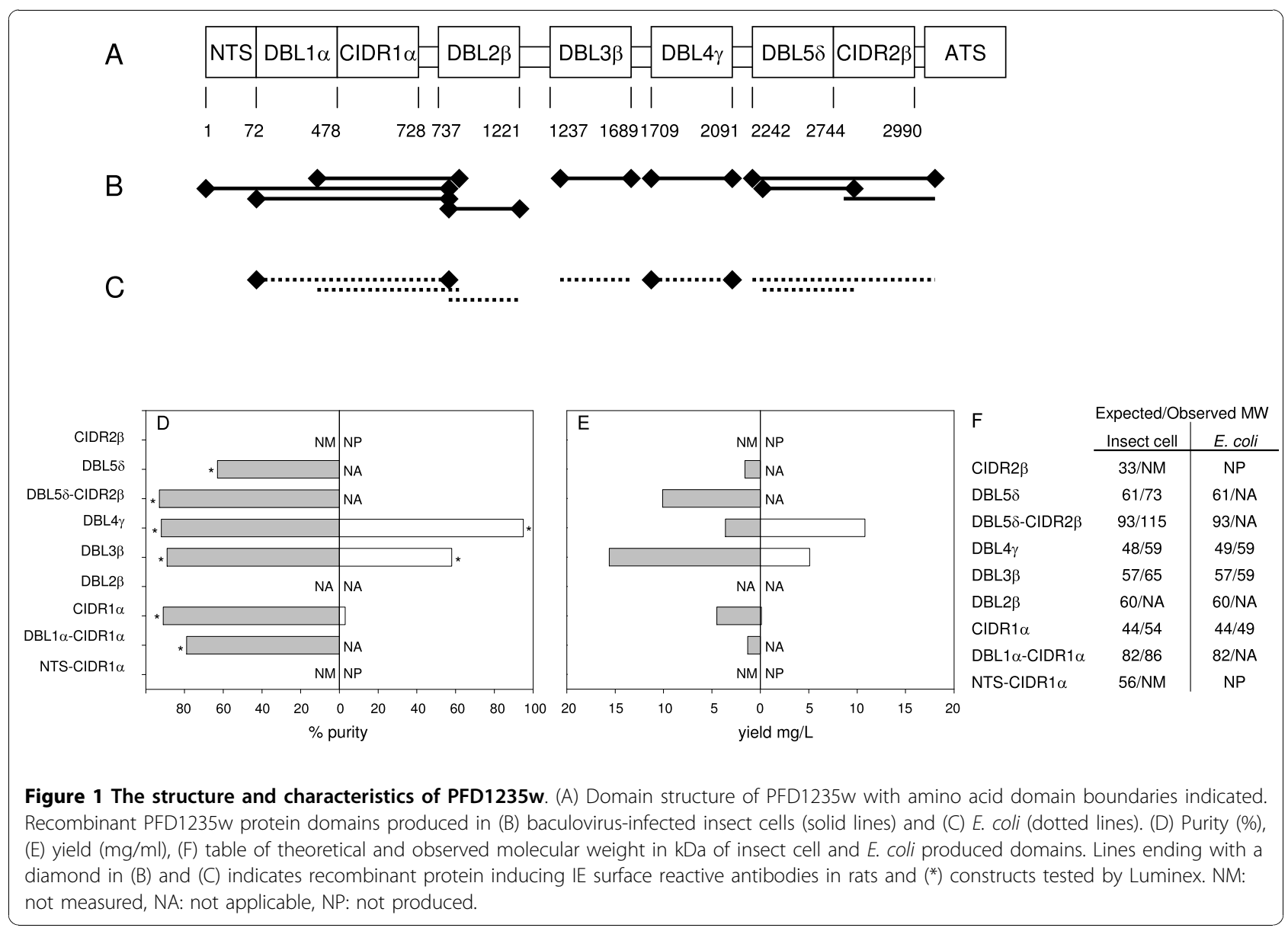




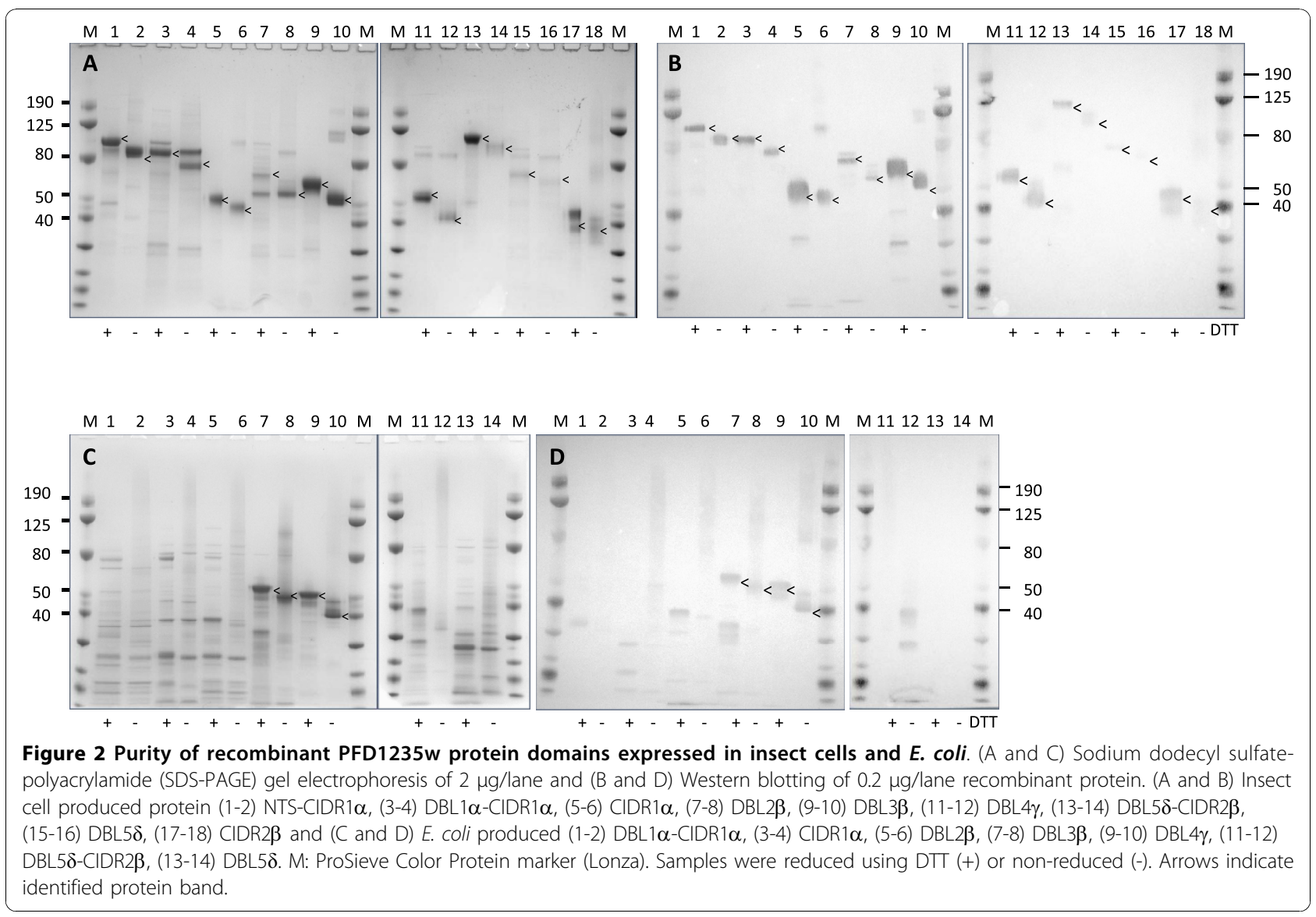

attempted expressed in insect cells, but not in E. coli. Of these proteins only DBL1 $\alpha$ failed to express.

\section{Recombinant PFD1235w protein induces IE surface reactive antibodies following immunization}

Identification of surface-exposed PfEMP1 domains accessible to antibodies has often been hampered by difficulties in generating specific surface-reactive antiPfEMP1 antibodies when using recombinant antigen as the immunogen. To address this issue for the particular PfEMP1 of interest, that associated with severe malaria in children [19], rats were immunized with recombinant PFD1235w protein domains expressed in insect cells (NTS-CIDR $1 \alpha$, DBL $1 \alpha-C I D R 1 \alpha$, CIDR $1 \alpha$, DBL $2 \beta$, DBL3 $\beta$, DBL4 $\gamma$, DBL5 $\delta$-CIDR2 $\beta$, DBL5 $\delta$, CIDR2 $\beta)$ or $E$. coli (DBL1 $\alpha$-CIDR1 $\alpha$, CIDR1 $\alpha$, DBL3 $\beta$, DBL4 $\gamma$ ).

Flow cytometry was used to test the ability of the induced antisera to recognize native PFD1235w on the surface of erythrocytes infected with a 3D7 PFD1235w parasite line selected for expression of high levels of this particular PfEMP1 [19]. Antisera raised against all the insect-cell produced domains were surface reactive with the $3 D 7_{\text {PFD1235w }}$ line, except antisera to CIDR2 $\beta$ (Figure 1 , Figure $3 \mathrm{~A}$, and Figure 4 ). In contrast, only antisera raised against DBL4 $\gamma$ produced in the $E$. coli Rosettagami B (DE3) strain contained IgG surface reactive with the surface of $3 \mathrm{D} 7_{\text {PFD1235w }}$ as did DBL1 $\alpha$-CIDR1 $\alpha$ antisera although this protein did not express at detectable levels (Figure 1 and Figure 3A).

This demonstrates that the majority of the seven different domains are surface-exposed and accessible to antibodies on the surface of infected human erythrocytes that are expressing the PFD1235w PfEMP1 antigen (Figure 4). An increased reactivity to the surface of infected erythrocytes was observed with antisera targeting the C-terminal parts of PFD1235w as compared to sera targeting the $\mathrm{N}$-terminal regions of this PfEMP1, irrespective of the production system (Figure 3B).

\section{Sharing of epitopes between insect cell and $E$. coli produced PFD1235w protein}

To compare the antibody epitope profile being exposed by insect cell and $E$. coli produced protein domains, rat antisera raised against the recombinant constructs was blocked by homologous as well as heterologous protein prior to flow cytometry testing (Figure 5). Both homologous and heterologous DBL $4 \gamma$ removed all IE surface antibody reactivity of both the heterologous and 


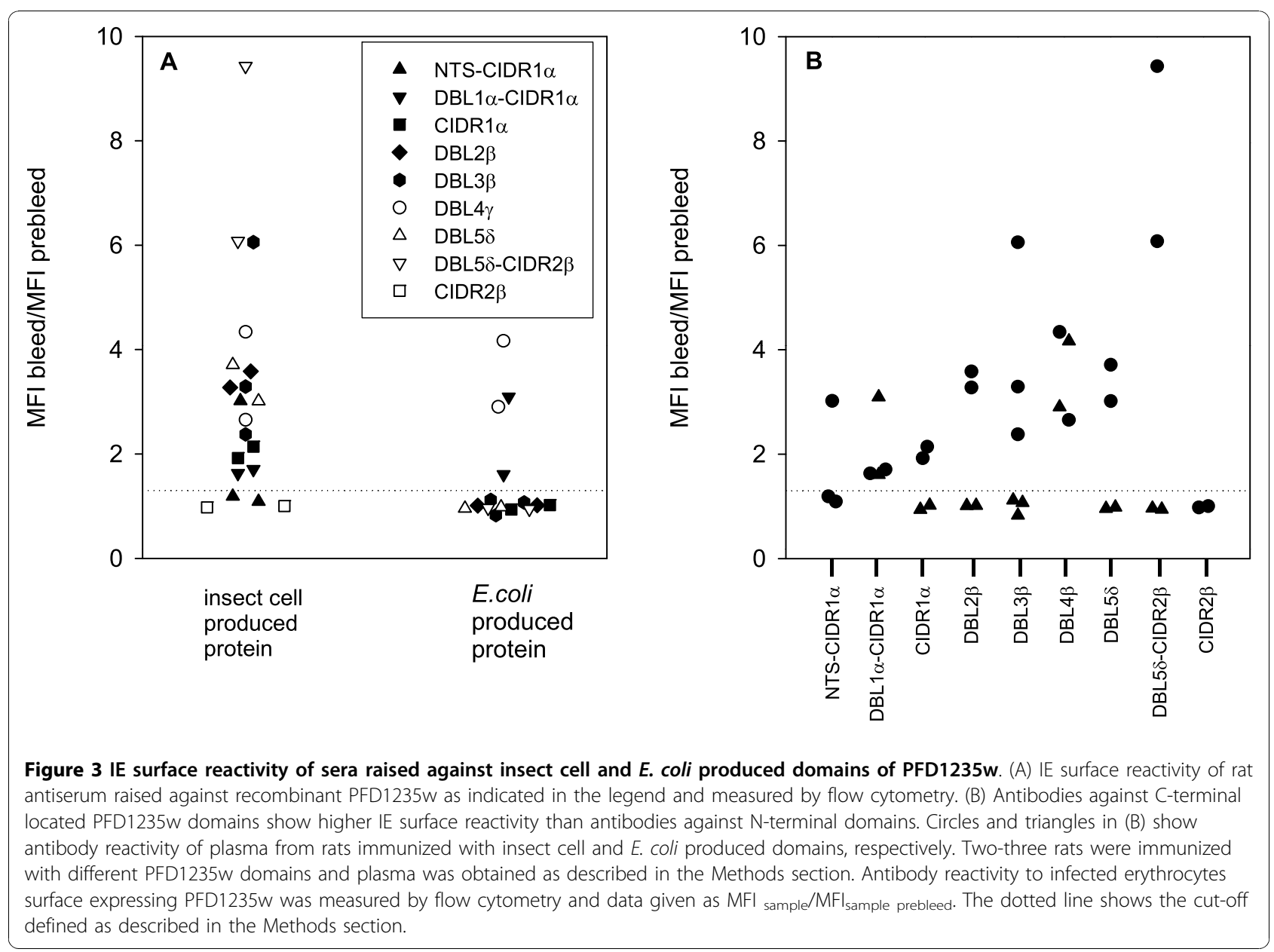

homologous anti-DBL4 $\gamma$ antisera (Figure 5B1 and 5B2) indicating that the two proteins are similarly folded and expose identical epitopes.

Similarly, E. coli produced DBL3 $\beta$ removed the surface antibody reactivity of the heterologous antisera, although this protein was unable to induce surface reactive antibodies in rats (Figure $5 \mathrm{C}$ ). By contrast, the baculovirus produced DBL1 $\alpha$-CIDR1 $\alpha$ was unable to block the reactivity of antisera raised against the heterologous protein. This indicates that there is a difference in the antibody epitopes being exposed in the rats following immunization (Figure 5A1 and 5A2). Doubling the concentration of blocking protein gave similar results. However, depletion using $E$. coli produced DBL1 $\alpha$-CIDR1 $\alpha$ protein did lead to a reduction in the reactivity of the heterologous antisera (Figure 5A1).

\section{Antibodies acquired during in vivo infections recognize recombinant PFD1235w domains}

A bead-based Luminex assay [24] was used to assess antibody reactivity of plasma samples from 180 Tanzanian children with a previous history of malaria [29] and
20 Danish blood donors with no previous exposure to malaria (Figure 6).

The average mean fluorescent intensity (MFI) of the antibody reactivity of the Danish control plasma samples towards the six insect cell produced proteins (DBL1 $\alpha$ CIDR $1 \alpha$, CIDR $1 \alpha$, DBL3 $\beta$, DBL $4 \gamma$, DBL5 $\delta$, DBL $5 \delta-$ CIDR2 $\beta)$ was low $\left(\mathrm{MFI}_{\text {average }}=[29 ; 80], \mathrm{MFI}_{\min }=[0 ; 5]\right.$, $\left.\mathrm{MFI}_{\max }=[84 ; 349]\right)$ compared to the antibody reactivity to the bacterial produced DBL3 $\beta\left(\mathrm{MFI}_{\text {average }}=151\right.$, MFI$\left.\min =6, M I_{\max }=525\right)$ and DBL4 $\gamma\left(M_{\text {Fiverage }}=351\right.$, MFI$\left.\min =4, M_{\max }=1042\right)$ domains. This probably reflects naturally acquired antibodies reacting with host contaminants present in the batch of DBL3 $\beta$ and DBL $4 \gamma$ produced in the $E$. coli system. As a result of this reactivity the MFI cut-off value based on the reactivity in Danish plasma was higher for the E. coli proteins than for the insect cell produced PfEMP1 domains.

A relationship between transmission intensities, age groups and percentage of responders was observed for all eight recombinant PfEMP1 domains (Figure 6). The plasma antibody reactivity also increased with age and with increasing transmission intensity. However, the two 

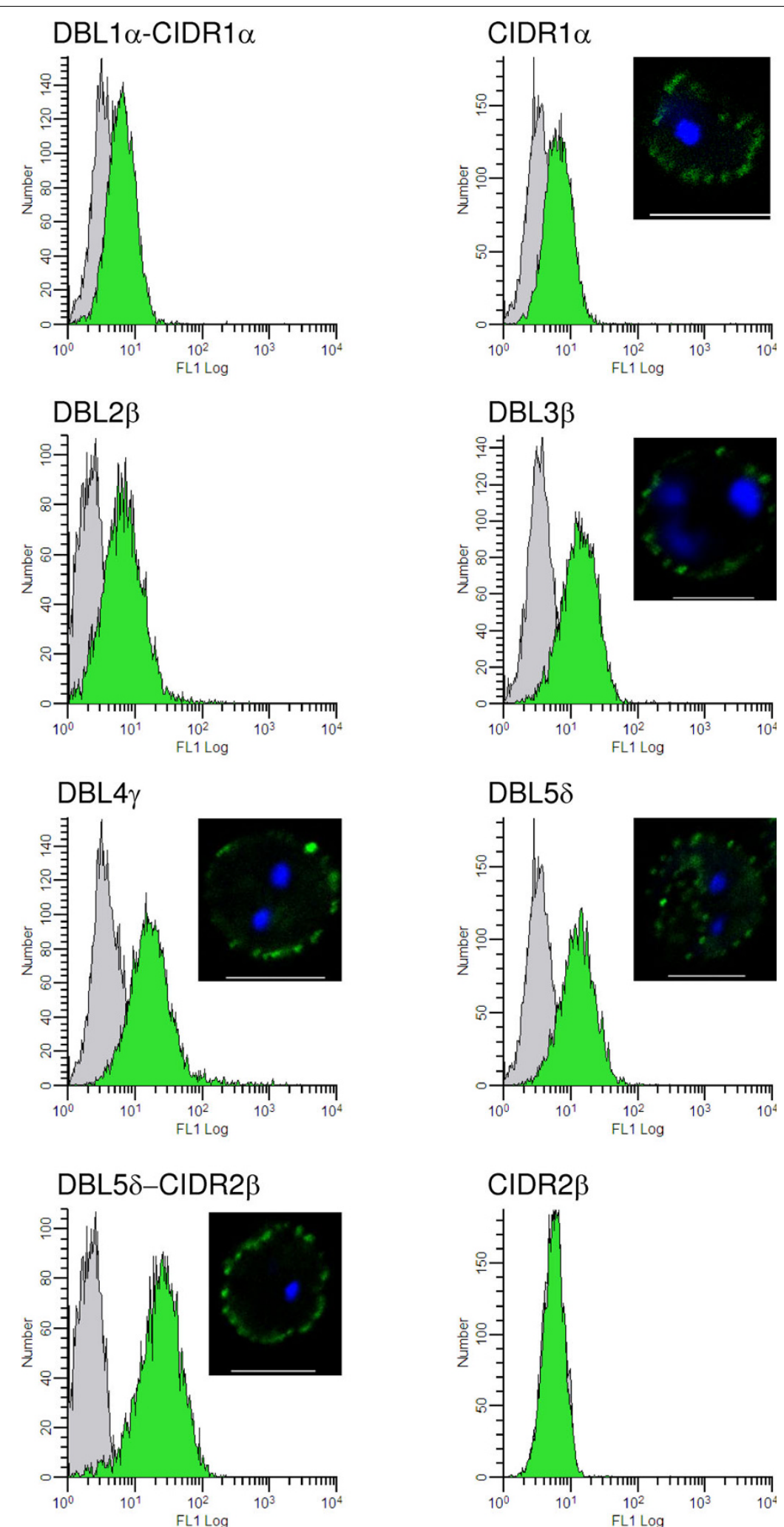

Figure 4 IE surface reactivity of sera raised against insect cell produced domains of PFD1235w. Shown is flow cytometry of PFD1235W expressing IE labelled with PFD1235w domains-specific rat antisera (green histograms) or with preimmunization control sera (grey histograms). The corresponding immunofluorescence microscopy surface reactivity is shown by inserts for antisera against CIDR1 $\alpha, D B L 3 \beta, D B L 4 \gamma, D B L 5 \delta$ and DBL5 $\delta$-CIDR2 $\beta$. Preimmunization sera and antisera against VAR2CSA [37] were negative in both assays. 

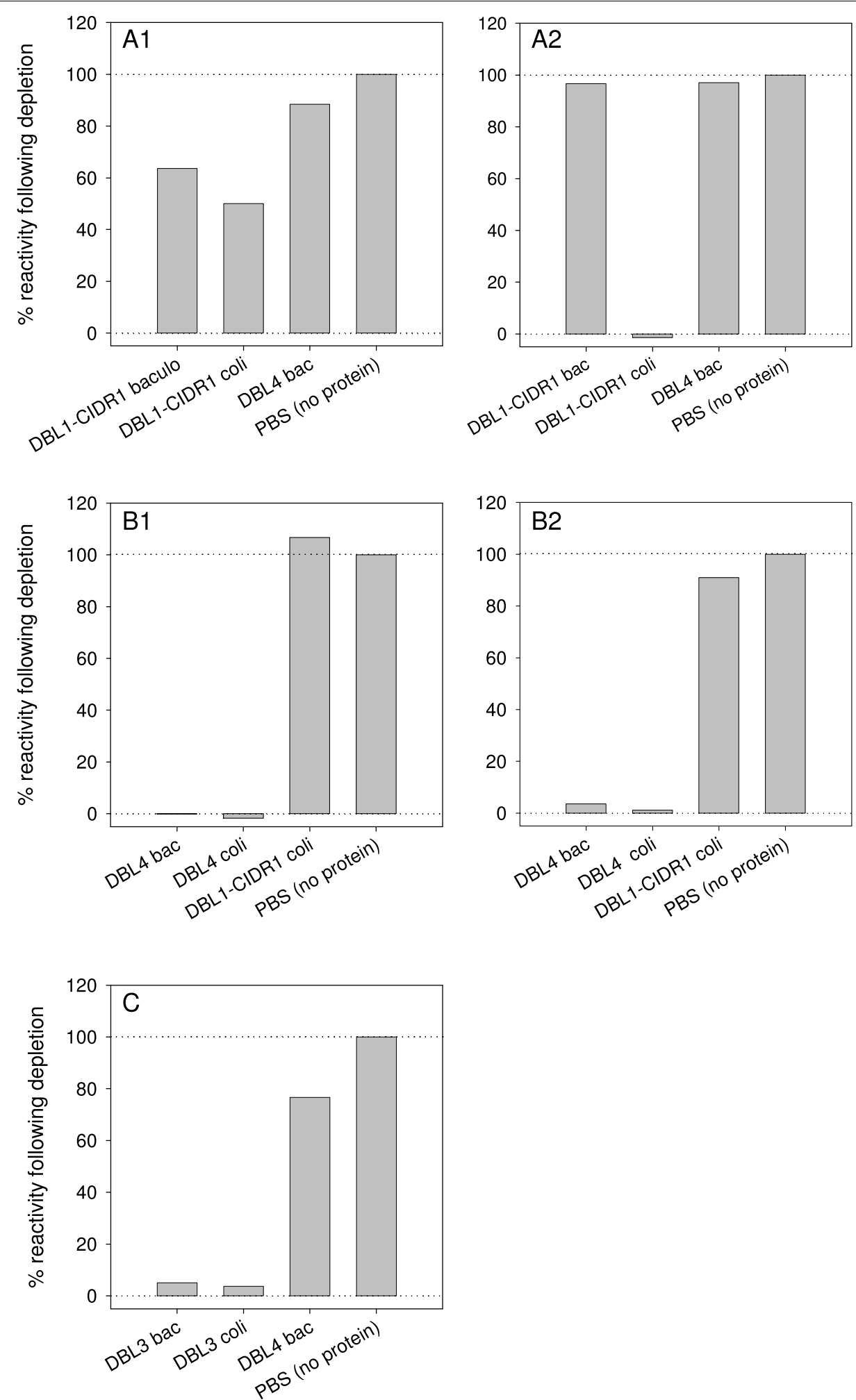

Figure 5 Recognition of native PFD1235w expressed on the surface of 3D7PFD1235w IE. The surface antibody reactivity of rat antisera raised against (A1 and B1) insect cells and (A2 and B2) E. coli produced DBL1 $\alpha$-CIDR1 $\alpha$ and DBL $4 \gamma$ was measured by flow cytometry. (C) The antibody surface reactivity of rat antisera raised against insect cell produced DBL33. Antisera were pre-incubated with excess homologous immunizing protein, heterologous produced protein, PBS or irrelevant protein as indicated. The percentage of reactivity left following depletion was calculated as described in the Methods section. 
bacterial produced proteins showed a lower percentage of positive responders compared to the homologous insect cell produced proteins. Of the 180 Tanzanian plasma samples $75 \%$ were either both positive or both negative in reactivity to insect cell and $E$. coli produced DBL3 $\beta$ and $65 \%$ both positive or both negative for DBL4 $\gamma$. The number of plasma samples showing positive antibody reactivity to insect cell produced, but not $E$. coli produced protein was markedly higher than the

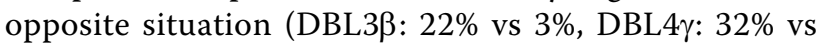
$2 \%)$.

\section{Discussion}

Identification of heterologous expression systems capable of expressing milligrams of soluble recombinant $P$. falciparum protein is a challenging process. In this study, the use of $E$. coli and insect cells were compared in producing 44-93 $\mathrm{kDa}$ single- and double protein domains encoded by the pfd1235w var gene. All seven constructs introduced into the baculovirus expression system produced recombinant protein, while three of seven constructs produced protein in the prokaryotic system (Figure 1). The high molecular weight $(\geq 57$ $\mathrm{kDa}$ ) of the four remaining $E$. coli constructs might explain why these did not express [4-6]. Decreasing the expression temperature to $4^{\circ} \mathrm{C}$ or varying concentrations of IPTG did not result in improved expression (data not shown).

Plasmodium falciparum proteins that are expressed in insoluble inclusion bodies in bacteria have previously been shown to be expressed in soluble form and capable of being made and purified in milligram amounts upon transfer to the baculovirus system [4]. However, the baculovirus expression system has yet to prove its worth when it comes to crystallography of PfEMP1 proteins, since five out of the six published crystal structures to date have been done on bacterially expressed recombinant proteins [30-35]. In addition, insect cells are known to sometimes hyper-glycosylate their recombinant products, a potential problem for expression of PfEMP1, as N- and O-glycosylations seem to occur at very low levels in $P$. falciparum [36].

The insect cell produced proteins were between 60$97 \%$ pure as compared to $3-95 \%$ for the $E$. coli proteins. This difference can probably be ascribed to the fact that the insect cell expressed proteins are purified from the cell media, as opposed to the bacterially expressed protein, which were purified from total cell extract. Degradation and co-purification of degradation products was observed with both expression systems, but was especially evident in the E. coli expression system. In addition, larger bands were visible in non-reducing lanes on Western blots for all the expressed recombinant proteins, possibly representing dimers and trimers.

Flow cytometry was used to test the ability of antisera to recognize native PFD1235w on the surface of erythrocytes infected with $3 D 7_{\text {PFD1235w }}$ a parasite line selected for high surface expression of PFD1235w [19]. Antisera raised against all of the seven baculovirus proteins and against PFD1235w DBL4 $\gamma$ and DBL1 $\alpha$-CIDR1 $\alpha$ domains produced in the Rosetta-gami B (DE3) E. coli strain showed IgG reactivity with the surface 3D7PFD1235w. In contrast to a previous study [37], this also showed the ability of the E. coli expression system to produce PfEMP1 protein domains with a three-dimensional structure sufficiently resembling that of the native

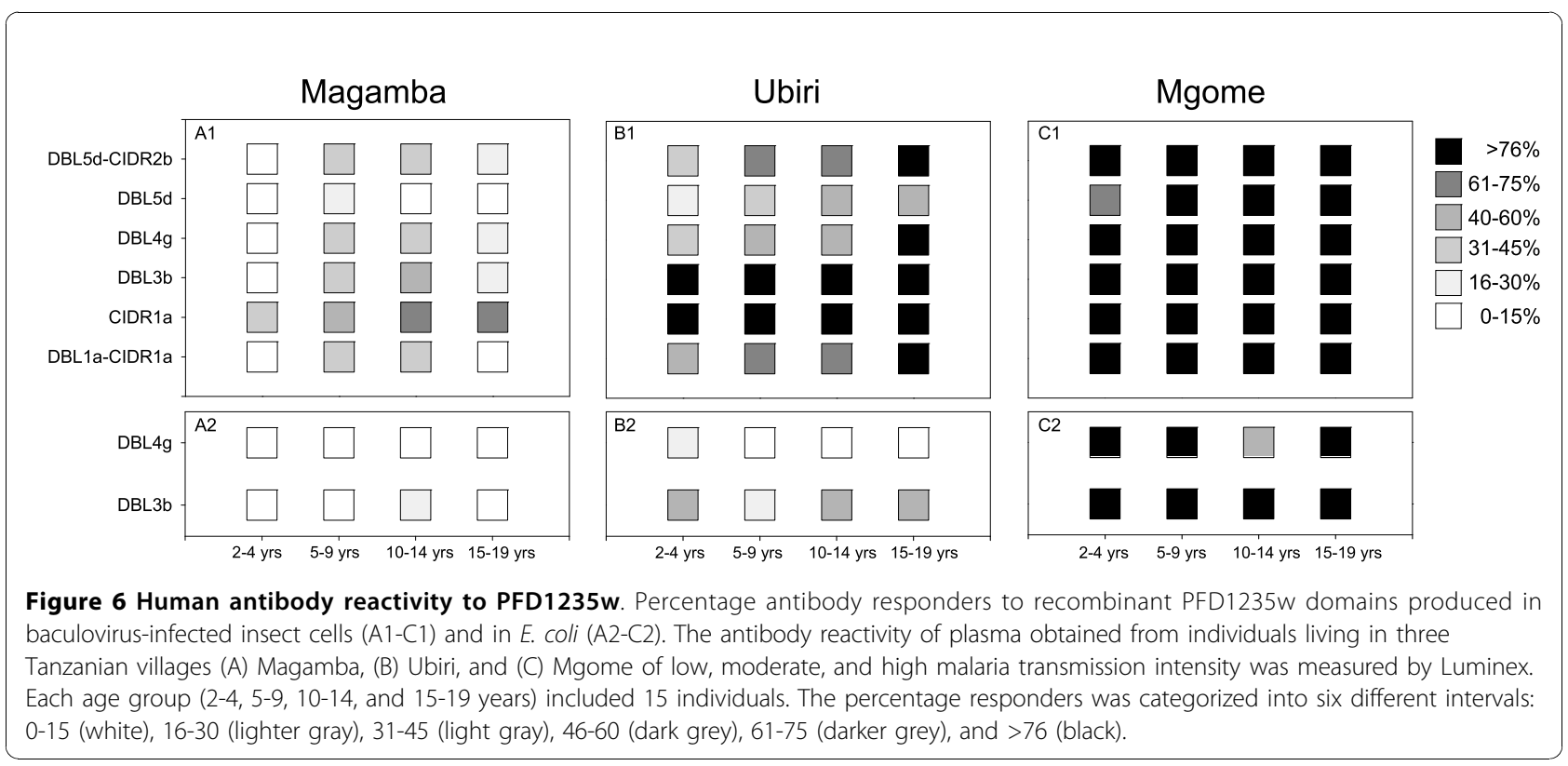


molecule to induce surface reactive antibodies following experimental immunization.

The insect cell produced DBL4 $\gamma$ consistently induce surface reactive IgG in rats, whereas this is not always observed with recombinant DBL4 $\gamma$ expressed by $E$. coli. This would indicate the $E$. coli expression system to be more sensitive to batch to batch variation.

To assess similarities in exposed antibody epitopes homologous and heterologous antisera were pre-incubated with recombinant DBL4 $\gamma$, DBL $3 \beta$ and DBL1 $\alpha-$ CIDR1 $\alpha$ produced in both expression systems prior to testing by flow cytometry (Figure 5). The two DBL4 $\gamma$ domains exposed identical epitopes as the reactivity of the antisera raised against insect cell produced DBL4 $\gamma$ could be abolished by pre-incubating with $E$. coli produced DBL4 $\gamma$ and vice versa (Figure 5B1 and 5B2). Similarly, DBL3 $\beta$ produced in $E$. coli abolished the reactivity of the heterologous antisera following depletion although this protein did not induce surface reactive antibodies following immunization of rats. However, this was not the case for the DBL1 $\alpha$-CIDR1 $\alpha$ antisera indicating that the insect and bacterial derived proteins were fundamentally different due to differences in folding and/or posttranslational modifications. These results show that most PFD1235w domains are surface exposed and accessible to antibodies in the native molecule as expressed by IE and that induction of surface reactive IgG seem critically dependent on a correct three-dimensional structure of the antigen used for immunization, a structure which is more often achieved in the eukaryotic compared to the prokaryotic system used. Depletion of DBL1 $\alpha$-CIDR $1 \alpha$ and DBL $5 \delta$-CIDR $2 \beta$ antisera using either CIDR $1 \alpha$, DBL5 $\delta$ or CIDR2 $\beta$ protein produced in insect cells show a reduced reactivity by FACS. This strongly indicates DBL1 $\alpha$ and CIDR2 $\beta$ to be similarly exposed on the native PFD1235w exported to the surface of IE.

Six of the seven insect cell and two of the E. coli produced proteins were used in a bead based Luminex assay to assess the antibody reactivity of 180 plasma samples collected from individuals with a previous exposure of malaria and living in a high (Mgome), moderate (Ubiri), and low (Magamba) malaria transmission area of Tanzania [23]. The $\mathrm{MFI}_{\text {cut-off }}$ value for the bacterial derived proteins in the Luminex analysis was considerable higher than their homologous counterparts from the baculovirus expression system. This cannot be explained by reactivity against the $\mathrm{V} 5$ tag as all proteins irrespective of expression system carry this, but is more likely a consequence of the low purity of the bacterial recombinant proteins samples.

Although the $E$. coli produced DBL3 $\beta$ did not induce any surface reactive antibodies in rats both domains were recognized by African sera in the Luminex assay. However, at a reduced level as compared to the equivalent insect cell produced protein (Figure 6). All proteins irrespective of production system were recognized by plasma antibodies in an age and transmission dependent manner. This correlation between malaria transmission intensity, age and acquisition of antibodies is in line with our previous finding on antibody responses to PFD1235w [20].

\section{Conclusions}

This study, assessed the use of a eukaryotic and prokaryotic system for expression of PFD1235w protein and found the insect cells more reliable and superior to E. coli in producing recombinant PfEMP1 domains that generates IE surface reactive antibodies following immunization of rats.

\section{Additional material}

Additional file 1: Table 1. Primers used for amplification of DNA encoding PFD1235w domains. The table provides information on primers used for PCR amplification of amplicons encoding different PFD1235w protein domains.

\section{Abbreviations}

IE: infected erythrocyte; ICAM1: intracellular adhesion molecule 1; MSP1: merozoite surface protein 1; PfEMP1: Plasmodium falciparum erythrocyte membrane protein 1; NTS: N-terminal segment; DBL: Duffy-binding like domain; CIDR: cysteine-rich interdomain;

\section{Acknowledgements and Funding}

We are grateful to all the individuals who donated plasma for this study and their parents/guardians as well as the village helpers and health management teams in Tanzania. The study received financial support from the Danish Council for Health Science Research (grant no. 271-05-0427), the Danish Research Council in Technology and Innovation (grant no. 274-060440), the Foundation from the National Institute of Health through the Grand Challenges in Global Health initiative (grant UC-3550), and the University of Copenhagen (Programme of Excellence in Membrane Topology and Quaternary Structure of Key Membrane Proteins Involved in Plasmodium falciparum Malaria Pathogenesis and Immunity). ATRJ is supported by the Howard Hughes Medical Institute (grant no. 55005511). MEV and LJ are supported by The Lundbeck Foundation (grant 96/06 and R9-A840). We thank Michael Alifrangis and Ulla Abildtrup for genotyping of parasites and Christina Holm and Mette Ulla Madsen for excellent technical assistance. Ali Salanti is thanked for providing VAR2CSA antibodies.

\section{Author details}

${ }^{1}$ Centre for Medical Parasitology, Department of International Health, Immunology and Microbiology, Faculty of Health Sciences, University of Copenhagen and Department of Infectious Diseases, Copenhagen University Hospital (Rigshospitalet), CSS Oester Farimagsgade 5, Building 22 \& 23, PO 2099, 1014 Copenhagen K, Denmark. National Institute for Medical Research, Tanga Centre, Tanga, Tanzania. ${ }^{3}$ Institute of Infection and Immunology Research, School of Biology, University of Edinburgh, West Mains Road, Edinburgh, EH9 3JT, Scotland, UK.

\section{Authors' contributions}

MEV, AB, GA, DB, LJ, ATRJ designed the study and performed laboratory work, JPL, LSV and TGT organized the field work. ATRJ and MEV wrote the manuscript. $A B, G A, D E A, L J, T$ helped to draft the manuscript. All authors have read and approved the final manuscript and contributed significantly to this work 


\section{Competing interests}

The authors declare that they have no competing interests.

Received: 27 August 2010 Accepted: 15 November 2010

Published: 15 November 2010

\section{References}

1. WHO: World malaria report. 2008, 1-32.

2. Gardner MJ, Hall N, Fung E, White O, Berriman M, Hyman RW, Carlton JM, Pain A, Nelson KE, Bowman S, Paulsen IT, James K, Eisen JA, Rutherford K, Salzberg SL, Craig A, Kyes S, Chan MS, Nene V, Shallom SJ, Suh B, Peterson J, Angiuoli S, Pertea M, Allen J, Selengut J, Haft D, Mather MW, Vaidya AB, Martin DM, Fairlamb AH, Fraunholz MJ, Roos DS, Ralph SA, McFadden Gl, Cummings LM, Subramanian GM, Mungall C, Venter JC, Carucci DJ, Hoffman SL, Newbold C, Davis RW, Fraser CM, Barrell B: Genome sequence of the human malaria parasite Plasmodium falciparum. Nature 2002, 419:498-511.

3. Birkholtz LM, Blatch G, Coetzer TL, Hoppe HC, Human E, Morris EJ, Ngcete Z, Oldfield L, Roth R, Shonhai A, Stephens L, Louw Al: Heterologous expression of plasmodial proteins for structural studies and functional annotation. Malar J 2008, 7:197.

4. Mehlin C, Boni E, Buckner FS, Engel L, Feist T, Gelb MH, Haji L, Kim D, Liu C, Mueller N, Myler PJ, Reddy JT, Sampson JN, Subramanian E, Van Voorhis WC, Worthey E, Zucker F, Hol WG: Heterologous expression of proteins from Plasmodium falciparum: results from 1000 genes. Mol Biochem Parasitol 2006, 148:144-160.

5. Aguiar JC, LaBaer J, Blair PL, Shamailova VY, Koundinya M, Russell JA, Huang F, Mar W, Anthony RM, Witney A, Caruana SR, Brizuela L, Sacci JB Jr, Hoffman SL, Carucci DJ: High-throughput generation of P. falciparum functional molecules by recombinational cloning. Genome Res 2004, 14:2076-2082

6. Vedadi M, Lew J, Artz J, Amani M, Zhao Y, Dong A, Wasney GA, Gao M, Hills T, Brokx S, Qiu W, Sharma S, Diassiti A, Alam Z, Melone M, Mulichak A, Wernimont A, Bray J, Loppnau P, Plotnikova O, Newberry K, Sundararajan E, Houston S, Walker J, Tempel W, Bochkarev A, Kozieradzki I, Edwards A, Arrowsmith C, Roos D, Kain K, Hui R: Genome-scale protein expression and structural biology of Plasmodium falciparum and related Apicomplexan organisms. Mol Biochem Parasitol 2007, 151:100-110.

7. Kost TA, Condreay JP, Jarvis DL: Baculovirus as versatile vectors for protein expression in insect and mammalian cells. Nat Biotechnol 2005, 23:567-575.

8. Leung WH, Meng ZQ, Hui G, Ho WK: Expression of an immunologically reactive merozoite surface protein (MSP-1(42)) in E. coli. Biochim Biophys Acta 2004, 1675:62-70.

9. Chang SP, Gibson HL, Lee-Ng CT, Barr PJ, Hui GS: A carboxyl-terminal fragment of Plasmodium falciparum gp195 expressed by a recombinant baculovirus induces antibodies that completely inhibit parasite growth. $J$ Immunol 1992, 149:548-555.

10. Barfod L, Bernasconi NL, Dahlback M, Jarrossay D, Andersen PH, Salanti A, Ofori MF, Turner L, Resende M, Nielsen MA, Theander TG, Sallusto F, Lanzavecchia A, Hviid L: Human pregnancy-associated malaria-specific B cells target polymorphic, conformational epitopes in VAR2CSA. Mol Microbiol 2007, 63:335-347.

11. Daly $T M$, Long CA: Humoral response to a carboxyl-terminal region of the merozoite surface protein-1 plays a predominant role in controlling blood-stage infection in rodent malaria. J Immunol 1995, 155 : 236-243.

12. Chang SP, Case SE, Gosnell WL, Hashimoto A, Kramer KJ, Tam LQ, Hashiro CQ, Nikaido CM, Gibson HL, Lee-Ng CT, Barr PJ, Yokota BT, Hut GS: A recombinant baculovirus 42-kilodalton C-terminal fragment of Plasmodium falciparum merozoite surface protein 1 protects Aotus monkeys against malaria. Infect Immun 1996, 64:253-261.

13. Smith JD, Chitnis CE, Craig AG, Roberts DJ, Hudson-Taylor DE, Peterson DS, Pinches R, Newbold Cl, Miller LH: Switches in expression of Plasmodium falciparum var genes correlate with changes in antigenic and cytoadherent phenotypes of infected erythrocytes. Cell 1995, 82:101-110.

14. Roberts DJ, Craig AG, Berendt AR, Pinches R, Nash G, Marsh K, Newbold Cl: Rapid switching to multiple antigenic and adhesive phenotypes in malaria. Nature 1992, 357:689-692.

15. Girard MP, Reed ZH, Friede M, Kieny MP: A review of human vaccine research and development: malaria. Vaccine 2007, 25:1567-1580.
16. Kyes $S$, Horrocks $P$, Newbold C: Antigenic variation at the infected red cell surface in malaria. Annu Rev Microbiol 2001, 55:673-707.

17. Smith JD, Subramanian G, Gamain B, Baruch DI, Miller LH: Classification of adhesive domains in the Plasmodium falciparum erythrocyte membrane protein 1 family. Mol Biochem Parasitol 2000, 110:293-310.

18. Lavstsen T, Salanti A, Jensen AT, Arnot DE, Theander TG: Sub-grouping of Plasmodium falciparum 3D7 var genes based on sequence analysis of coding and non-coding regions. Malar J 2003, 2:27.

19. Jensen AT, Magistrado P, Sharp S, Joergensen L, Lavstsen T, Chiucchiuini A, Salanti A, Vestergaard LS, Lusingu JP, Hermsen R, Sauerwein R, Christensen J, Nielsen MA, Hviid L, Sutherland C, Staalsoe T, Theander TG: Plasmodium falciparum associated with severe childhood malaria preferentially expresses PfEMP1 encoded by group A var genes. J Exp Med 2004, 199:1179-1190.

20. Lusingu JP, Jensen AT, Vestergaard LS, Minja DT, Dalgaard MB, Gesase $S$, Mmbando BP, Kitua AY, Lemnge MM, Cavanagh D, Hviid L, Theander TG: Levels of plasma immunoglobulin $G$ with specificity against the cysteine-rich interdomain regions of a semiconserved Plasmodium falciparum erythrocyte membrane protein 1, VAR4, predict protection against malarial anemia and febrile episodes. Infect Immun 2006, 74:2867-2875.

21. Joergensen L, Turner L, Magistrado P, Dahlback MA, Vestergaard LS, Lusingu JP, Lemnge M, Salanti A, Theander TG, Jensen AT: Limited crossreactivity among domains of the Plasmodium falciparum clone 3D7 erythrocyte membrane protein 1 family. Infect Immun 2006, 74:6778-6784.

22. Dahlback M, Rask TS, Andersen PH, Nielsen MA, Ndam NT, Resende M, Turner L, Deloron P, Hviid L, Lund O, Pedersen AG, Theander TG, Salanti A: Epitope mapping and topographic analysis of VAR2CSA DBL3X involved in P. falciparum placental sequestration. PLoS Pathog 2006, 2:e124.

23. Lusingu JP, Vestergaard LS, Mmbando BP, Drakeley CJ, Jones C, Akida J, Savaeli ZX, Kitua AY, Lemnge MM, Theander TG: Malaria morbidity and immunity among residents of villages with different Plasmodium falciparum transmission intensity in North-Eastern Tanzania. Malar J 2004, 3:26.

24. Cham GK, Kurtis J, Lusingu J, Theander TG, Jensen AT, Turner L: A semiautomated multiplex high-throughput assay for measuring $\lg G$ antibodies against Plasmodium falciparum erythrocyte membrane protein 1 (PfEMP1) domains in small volumes of plasma. Malar J 2008, 7:108

25. Staalsoe T, Giha HA, Dodoo D, Theander TG, Hviid L: Detection of antibodies to variant antigens on Plasmodium falciparum-infected erythrocytes by flow cytometry. Cytometry 1999, 35:329-336.

26. Snounou G, Zhu X, Siripoon N, Jarra W, Thaithong S, Brown KN, Viriyakosol S: Biased distribution of $\mathrm{msp1}$ and $\mathrm{msp2}$ allelic variants in Plasmodium falciparum populations in Thailand. Trans R Soc Trop Med Hyg 1999, 93:369-374.

27. Staalsoe $T$, Nielsen MA, Vestergaard LS, Jensen AT, Theander TG, Hviid L: In vitro selection of Plasmodium falciparum 3D7 for expression of variant surface antigens associated with severe malaria in African children. Parasite Immunol 2003, 25:421-427.

28. Bengtsson D, Sowa KM, Salanti A, Jensen AT, Joergensen L, Turner $L$, Theander TG, Arnot DE: A method for visualizing surface-exposed and internal PfEMP1 adhesion antigens in Plasmodium falciparum infected erythrocytes. Malar J 2008, 7:101.

29. Joergensen L, Vestergaard LS, Turner L, Magistrado P, Lusingu JP, Lemnge M, Theander TG, Jensen AT: 3D7-Derived Plasmodium falciparum erythrocyte membrane protein 1 is a frequent target of naturally acquired antibodies recognizing protein domains in a particular pattern independent of malaria transmission intensity. J Immunol 2007, 178:428-435.

30. Higgins MK: The structure of a chondroitin sulfate-binding domain important in placental malaria. J Biol Chem 2008, 283:21842-21846.

31. Singh $K$, Gittis AG, Nguyen P, Gowda DC, Miller LH, Garboczi DN: Structure of the DBL3x domain of pregnancy-associated malaria protein VAR2CSA complexed with chondroitin sulfate A. Nat Struct Mol Biol 2008, 15:932-938.

32. Khunrae P, Philip JM, Bull DR, Higgins MK: Structural comparison of two CSPG-binding DBL domains from the VAR2CSA protein important in malaria during pregnancy. J Mol Biol 2009, 393:202-213.

33. Singh SK, Hora R, Belrhali H, Chitnis CE, Sharma A: Structural basis for Duffy recognition by the malaria parasite Duffy-binding-like domain. Nature 2006, 439:741-744. 
34. Klein MM, Gittis AG, Su HP, Makobongo MO, Moore JM, Singh S, Miller LH, Garboczi DN: The cysteine-rich interdomain region from the highly variable Plasmodium falciparum erythrocyte membrane protein-1 exhibits a conserved structure. PLOS Pathog 2008, 4:e1000147.

35. Tolia NH, Enemark EJ, Sim BK, Joshua-Tor L: Structural basis for the EBA175 erythrocyte invasion pathway of the malaria parasite Plasmodium falciparum. Cell 2005, 122:183-193.

36. Gowda DC, Davidson EA: Protein glycosylation in the malaria parasite. Parasitol Today 1999, 15:147-152.

37. Barfod L, Nielsen MA, Turner L, Dahlback M, Jensen AT, Hviid L, Theander TG, Salanti A: Baculovirus-expressed constructs induce immunoglobulin $\mathrm{G}$ that recognizes VAR2CSA on Plasmodium falciparuminfected erythrocytes. Infect Immun 2006, 74:4357-4360.

doi:10.1186/1475-2875-9-325

Cite this article as: Victor et al:: Insect cells are superior to Escherichia coli in producing malaria proteins inducing lgG targeting PfEMP1 on infected erythrocytes. Malaria Journal 2010 9:325.

\section{Submit your next manuscript to BioMed Central and take full advantage of:}

- Convenient online submission

- Thorough peer review

- No space constraints or color figure charges

- Immediate publication on acceptance

- Inclusion in PubMed, CAS, Scopus and Google Scholar

- Research which is freely available for redistribution

Submit your manuscript at www.biomedcentral.com/submit 